\title{
PENERAPAN METODE FUZZY ANALYTIC HIERARCHY PROCESS DENGAN METODE PERCEPTRON PADA PENENTUAN KLASIFIKASI EVALUASI PENERIMAAN MOBIL
}

Page | 1

\author{
Eva Julia Gunawati Harianja ${ }^{1}$, Gortap Lumbantoruan ${ }^{2}$ \\ ${ }^{I}$ Manajemen Informatika, Universitas Methodist Indonesia \\ Jl.Hang Tuah No 8 Medan 20152, Sumatera Utara- Indonesia \\ ${ }^{2}$ Komputerisasi Akuntansi, Universitas Methodist Indonesia \\ Jl.Hang Tuah No 8 Medan 20152, Sumatera Utara-Indonesia \\ I'graziedamanik@gmail.com, ${ }^{2}$ lumbantoruan.gortap@gmail.com
}

\begin{abstract}
Abstrak - Penelitian ini mengusulkan sebuah format pengambilan keputusan berbasis metode Analythical Hierarchy Process (AHP) yang adaptif. Metode AHP klasik ini memiliki keterbatasan yang tidak dapat mencerminkan pemikiran manusia sebagai pengambil keputusan dalam menangani informasi yang bersifat kualitatif atau tidak tepat. Untuk itu teori himpunan fuzzy sangat disarankan untuk mengatasi masalah jenis informasi kualitatif, tidak tepat atau bahkan masalah keputusan terstruktur yang buruk. Permasalahan yang sering terjadi saat membentuk matriks perbandingan berpasangan pada teknik AHP sering tidak dapat memberikan nilai perbandingan yang konsisten, khususnya untuk masalah dengan jumlah kriteria dan alternatif yang banyak. Pada penelitian ini untuk menghindari masalah ketidak konsistensian yang terjadi pada metode AHP akan di terapkan metode perceptron dengan model jaringan lapis banyak (multilayer) dalam menentukan pemilihan alternatif. Hal ini diharapkan dapat meminimalisir pembentukan matriks perbandingan berpasangan. Penerapan metode Fuzzy Analiythical Hierarchy Process (FAHP) dan metode perceptron pada kasus penentuan klasifikasi evaluasi penerimaan mobil ini diharapkan mampu memberikan nilai akurasi atau ketepatan klasifikasi.
\end{abstract}

Kata Kunci- Fuzzy AHP, perceptron, evaluasi penerimaan mobil.

\section{PENDAHULUAN}

Permasalahan pengambilan keputusan seringkali menjadi hal yang tidak mudah dipecahkan. Metode Fuzzy Analytic Hierarchy Process (FAHP) merupakan salahsatu teknik pengambilan keputusan yang telah banyak diterapkan. Namun metode FAHP masih memiliki kelemahan yaitu dalam menangani kasus dengan jumlah kriteria dan alternatif yang banyak, karena Fuzzy Analytic Hierarchy Process masih menerapkan prinsip dasar metode AHP dimana proses penghitungan bobot dilakukan setelah membentuk matriks perbandingan berpasangan. Pada metode Analytic Hierarchy Process (AHP) sering tidak dapat memberikan nilai perbandingan yang konsisten, khususnya untuk masalah dengan jumlah kriteria dan alternatif yang banyak [1] karena jumlah perbandingan berpasangan yang akan dibuat, dapat menjadi sangat besar dengan ukuran (n(n-1)/2) sehingga akan memakan waktu yang cukup lama [2].

Pada penelitian ini, metode perceptron menggunakan jaringan multilayer feedforeward diterapkan untuk mengoptimasi Fuzzy Analytic Hierarchy Process (FAHP) untuk mengatasi masalah pembentukan matriks perbandingan berpasangan (Pairwise Comparison Matrix) yang kompleks dalam rangka meningkatkan akurasi hasil klasifikasi evaluasi penerimaan mobil.

\section{TINJAUAN PUSTAKA}

\section{A. Analytic Hierarchy Proces}

Metode Analytic Hierarchy Process (AHP) dikembangkan oleh seorang ahli matematika [3]. Metode ini membantu memecahkan persoalan yang kompleks dengan menstruktur hirarki kriteria, dan dengan berbagai pertimbangan guna mengembangkan bobot atau prioritas.

Metode AHP didasarkan pada tiga prinsip yaitu struktur model, komparatif penilaian alternatif dan kriteria serta kombinasi dari prioritas. Prinsip kerja AHP adalah penyederhanaan suatu persoalan kompleks yang tidak terstruktur, strategi, dan dinamik menjadi bagian-bagiannya yang teratur dalam suatu hirarki. Kemudian tingkat kepentingan setiap variabel diberi nilai numerik secara subjektif tentang arti penting variabel tersebut secara relatif dibandingkan dengan variabel lain. Dari berbagai pertimbangan tersebut kemudian dilakukan sintesa untuk menetapkan variabel yang memiliki prioritas tinggi dan berperan untuk mempengaruhi hasil pada sistem tersebut

\section{B. Fuzzy Analytic Hierarchy Proces (FAHP)}

Metode Fuzzy Analytic Hierarchy Process (FAHP) pertama kali diusulkan oleh seorang peneliti bernama Chang dan merupakan perpanjangan langsung dari metode AHP yang diciptakan oleh Saaty yang terdiri 
dari unsur-unsur matriks yang diwakili oleh bilangan fuzzy. Metode FAHP menggunakan rasio fuzzy yang disebut Triangular Fuzzy Number (TFN) dan digunakan dalam proses fuzzifikasi. TFN terdiri dari tiga fungsi keanggotaan, yaitu nilai terendah $(l)$, nilai

Page $\mid 2$ tengah $(m)$, dan nilai tertinggi $(u)$

\section{Mencari bobot kriteria dengan metode FAHP [4]}

Dalam mencari bobot dengan metode Fuzzy Analytic Hierarchy Proces (FAHP), langkahlangkahnya adalah sebagai berikut:

1. Hitung nilai fuzzy syntethic content dengan rumus berikut:

$$
S_{i}=\sum_{j=1}^{m} M_{g_{i}}^{j} \times\left[\sum_{i=1}^{n} \sum_{j=1}^{m} M_{g_{i}}^{j}\right]^{-1}
$$

Dimana

$$
\sum_{j=1}^{m} M_{g_{i}}^{j}=\left(\sum_{j=1}^{m} l_{j}, \quad \sum_{j=1}^{m} m_{j}, \quad \sum_{j=1}^{m} u_{j}\right)
$$

Sedangkan untuk memperoleh nilai

$$
\left[\sum_{i=1}^{n} \sum_{j=1}^{m} M_{g_{i}}^{j}\right]^{-1}
$$

dilakukan operasi penjumlahan untuk keseluruhan bilangan triangular fuzzy

$$
M_{g i}^{j}(j=1,2, \ldots, m)
$$

yaitu dengan rumus berikut:

$$
\begin{aligned}
& \sum_{i=1}^{n} \sum_{j=1}^{m} M_{g_{i}}^{j}= \\
& \left(\sum_{i=1}^{n} \sum_{j=1}^{m} l_{j}, \quad \sum_{i=1}^{n} \sum_{j=1}^{m} m_{j}, \quad \sum_{i=1}^{n} \sum_{j=1}^{m} u_{j}\right) \\
& \sum_{i=1}^{n} \sum_{j=1}^{m} M_{g_{i}}^{j}= \\
& \left(\sum_{i=1}^{n} \sum_{j=1}^{m} l_{j}, \quad \sum_{i=1}^{n} \sum_{j=1}^{m} m_{j}, \quad \sum_{i=1}^{n} \sum_{j=1}^{m} u_{j}\right)
\end{aligned}
$$

$\left[\sum_{i=1}^{n} \sum_{j=1}^{m} M_{g i}^{j}\right]^{-1}=$

$\left(\frac{1}{\sum_{i=1}^{n} \sum_{j=1}^{m} u_{i j}}, \quad \frac{1}{\sum_{i=1}^{n} \sum_{j=1}^{m} m_{i j}} \quad \frac{1}{\sum_{i=1}^{n} \sum_{j=1}^{m} l_{i j}}\right)$ Untuk menghitung invers vektor dapat dilakukan dengan rumus:

$$
\begin{aligned}
& {\left[\sum_{i=1}^{n} \sum_{j=1}^{m} M_{g i}^{j}\right]^{-1}=} \\
& \left(\frac{1}{\sum_{i=1}^{n} \sum_{j=1}^{m} u_{i j}}, \frac{1}{\sum_{i=1}^{n} \sum_{j=1}^{m} m_{i j}} \frac{1}{\sum_{i=1}^{n} \sum_{j=1}^{m} l_{i j}}\right)
\end{aligned}
$$

2. Hitung perbandingan tingkat kemungkinan antara bilangan fuzzy untuk dua bilangan triangular

fuzzy $\mathrm{S}_{1}=\left(\mathrm{l}_{1}, \mathrm{~m}_{1}, \mathrm{u}_{1}\right)$ dan $\mathrm{S}_{2}=\left(\mathrm{l}_{2}, \mathrm{~m}_{2}, \mathrm{u}_{2}\right)$

dengan tingkat Kemungkinan $\left(S_{1} \geq S_{2}\right)$ dapat didefenisikan dengan persamaan:

$$
V\left(S_{1} \geq S_{2}\right)=\left\{\begin{array}{cc}
1, & \text { jika } m_{1} \geq m_{2} \\
0, & \text { jika } l_{2} \geq u_{1} \\
& l_{2}-u_{1} \\
\hline\left(m_{1}-\right. & \left.u_{1}\right)-\left(m_{2}-l_{2}\right)
\end{array}\right.
$$

3. $d^{\prime}(A i)=\min V(S i \geq S k)$ Hitung tingkat kemungkinan untuk bilangan fuzzy

$$
k=1,2, \ldots, n \quad ; k \neq i
$$

4. Normalisasikan vektor bobot, dengan persamaan

$$
d^{\prime}=\frac{d^{\prime}(A i)}{\sum_{i=1}^{n} d^{\prime}(A i)}
$$

Untuk $\mathrm{i}=1,2, \ldots, \mathrm{n}$

\section{Perceptron}

Perceptron merupakan salah satu metode pembelajaran terawasi (Supervise Learning Method) dalam Jaringan Saraf Tiruan (JST) yang umumnya digunakan untuk mengklasifikasikan suatu pola tertentu. Model jaringan perceptron ditemukan oleh Rosenblatt pada tahun 1962 dan Minsky-Papert tahun 1969 yang merupakan model yang memiliki pelatihan yang paling baik pada era tersebut.

Metode Multilayer Perceptron (MLP) atau perceptron multilapis adalah metode Artificial Neural Network (ANN) yang memiliki arsitektur jaringan yang terdiri sekurang-kurangnya 3 layer. Ketiga layer tersebut antara lain lapisan layer input, layer hidden dan layer output [5], [6]. Sama seperti metode-metode Artificial Neural Network (ANN) yang lain, metode ini bertujuan untuk mendapatkan vektor bobot yang paling fit dengan data latih.

Multilayer perceptron merupakan salah satu metode yang terdapat dalam neural network yang menggunakan nilai eror untuk memperbaiki nilai bobot. Multilayer Perceptron merupakan jaringan yang paling sering mempertimbangkan anggota dari keluarga jaringan syaraf tiruan. Multilayer Perceptron adalah jaringan syaraf tiruan feed-forward yang terdiri dari sejumlah neuron yang dihubungkan oleh bobotbobot penghubung. Neuron-neuron tersebut disusun dalam lapisan-lapisan yang terdiri dari satu lapisan input (input layer), satu atau lebih lapisan tersembunyi (hidden layer), dan satu lapisan output (output layer).

Model MLP memiliki layer neuron tambahan selain layer input dan output, yaitu hidden layer yang terletak di antara kedua layer tersebut. Jumlah hidden layer bervariasi tergantung dari tingkat kesulitan permasalahan yang ditangani oleh sistem. Arsitektur jaringan multilayer perceptron ditampilkan pada gambar 1 .

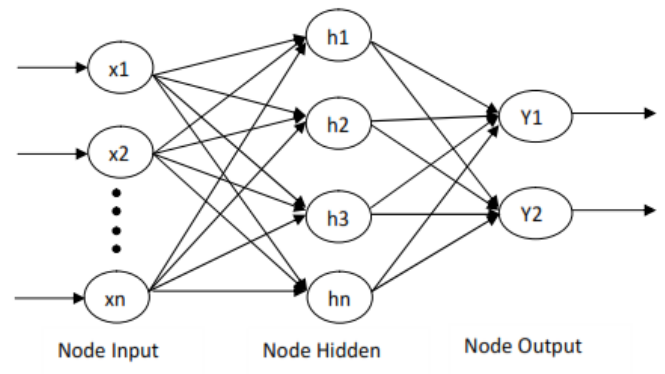

Gbr 1. Arsitektur Jaringan Multilayer Perceptron 
Dari gambar di atas, menunjukkan jumlah variabel input yang akan dilatih adalah x1-x12 yang merupakan nilai dari setiap atribut Buying, Maint, Doors, People, Lug_Boot Dan Safety. H1-hn menunjukkan jumlah lapisan tersembunyi di jaringan

Page|3 yang dibangun. Dan variabel y1-y2 adalah target output yang merupakan hasil dari pelatihan. Target hasil yang diharapkan dari pelatihan ini adalah dalam bentuk tipe kelas dalam Evaluasi Mobil ketika nilainya $\mathrm{y} 1=0$ dan $\mathrm{y} 2=0$ Unacc, jika y $1=0$ dan $\mathrm{y} 2=1$ adalah Acc, jika y1=1 dan y2=0 adalah Good maka jika y1 =1 dan y2 =1 adalah Vgood.

Dalam perancangan arsitektur Multilayer Perceptron ada beberapa hal yang perlu di perhatikan diantaranya adalah:

1. Menentukan Jumlah Neuron Input

2. Menentukan Jumlah Hidden Layer

3. Jumlah Neuron Hidden Layer

4. Jumlah Output

5. Fungsi Aktivasi yang digunakan

\section{Pelatihan Perceptron}

Pelatihan pada perceptron dilakukan dengan merubah nilai penimbangnya sehingga sesuai dengan kebutuhan yang dilakukan dengan membandingkan keluaran dari jaringan dengan targetnya. Algoritma dari perceptron adalah [7]:

1. Inisialisasi semua bobot bias, agar perhitungan menjadi sederhana, set bobot sama dengan nol)

Set learning rate $(\alpha)$ dengan $0<\alpha \leq 1$;

2. Selama kondisi berhenti bernilai false, lakukan langkah-langkah berikut:

a. Untuk setiap pasangan pembelajaran s-t, kerjakan:

Set input dengan nilai yang sama dengan vector input

$$
\mathrm{Xi}=\mathrm{si}
$$

b. Hitung respon untuk nilai output

$$
\begin{aligned}
& \text { net }=b+\sum_{i=1}^{n} x i w i \\
& y=\left\{\begin{array}{c}
-1, \text { net }<-\emptyset \\
0, \leq \text { net } \leq \emptyset \\
1, \text { net }>\emptyset,
\end{array}\right.
\end{aligned}
$$

c. Perbaiki bobot dan bias jika terjadi error:

Jika $\mathrm{y} \neq \mathrm{t}$ maka:

$\mathrm{Wi}($ baru $)=\mathrm{wi}($ lama $)+\alpha * \mathrm{t} * \mathrm{xi}$

$\mathrm{b}($ baru $)=\mathrm{b}($ lama $)+\alpha * \mathrm{t}$

jika tidak, maka:

$\mathrm{Wi}($ baru $)=$ wi $($ lama $)$

$\mathrm{b}($ baru $)=\mathrm{b}($ lama $)$

d. Tes kondisi berhenti, jika tidak terjadi perubahan bobot pada (i) maka kondisi berhenti akan bernilai true. Namun jika masih terjadi perubahan maka kondisi berhenti akan bernilai false

\section{PEMBAHASAN}

\section{A. Pra Proses Data}

Data Evaluasi Mobil berisi data nominal, data atribut, dan data kelas. Untuk melakukan pemrosesan data, dataset diubah menjadi data numerik. Konversi data nominal ke data numerik didasarkan pada nilai atribut dataset, dengan mentransformasi data nilai atribut menggunakan unary encoding dengan kombinasi angka 0 dan 1 . Hal ini dilakukan karena umumnya jaringan perceptron hanya dapat memproses data dalam bentuk angka.

TABEL I

NILAI ATRIBUT MASUKAN SETELAH TRANSFORMASI

\begin{tabular}{||c|c|c|c|c|c||}
\hline Buying & Maint & Doors & Persons & Lug_boot & Safety \\
\hline 0 & 0 & 0 & 0 & 0 & 0 \\
\hline 1 & 1 & 1 & 1 & 1 & 1 \\
\hline 10 & 10 & 10 & 10 & 10 & 10 \\
\hline 11 & 11 & 11 & & & \\
\hline
\end{tabular}

\section{B. Inisialisasi Data}

Proses inisialisasi dilakukan sebelum tahap pelatihan data (training). Inisialisasi ini bertujuan untuk menentukan nilai parameter jaringan yang telah dirancang sebelumnya. Parameter jaringan yang ditentukan adalah: banyak data yang dilatih (training), proses iterasi (epoch), kecepatan belajar (learning rate), jumlah layer, dan banyak data yang akan diuji.

\section{Matriks Perbandingan Skala TFN}

Matriks perbandingan (Pairwise Comparison Matrix) dibuat untuk membandingkan masing-masing atribut yang ada dengan perbandingan satu banding satu diantara tiap atribut, sehingga nantinya dapat diperoleh bobot relatif dari masing-masing atribut pada data evaluasi penerimaan mobil, yaitu buying, maint, doors, persons, lugboot dan safety. Perbandingan berpasangan dengan skala TFN seperti terlihat pada tabel II.

TABEL II

TABEL PERBANDINGAN BERPASANGAN ANTAR ATRIBUT SKALA TFN

\begin{tabular}{|l|c|c|c|c|c|c|}
\hline & Buying & Maint & Doors & Persons & Lugboot & Safety \\
\cline { 2 - 7 } & $(\mathrm{l}, \mathrm{m}, \mathrm{u})$ & $(1, \mathrm{~m}, \mathrm{u})$ & $(1, \mathrm{~m}, \mathrm{u})$ & $(1, \mathrm{~m}, \mathrm{u})$ & $(1, \mathrm{~m}, \mathrm{u})$ & $(1, \mathrm{~m}, \mathrm{u})$ \\
\hline Buying & $1,1,1$ & $1,2,3$ & $1,2,3$ & $1,2,3$ & $1,2,3$ & $1 / 4,1 / 3,1 / 2$ \\
\hline Maint & $1 / 3,1 / 2,1 / 1$ & $1,1,1$ & $1,2,3$ & $1,2,3$ & $1,2,3$ & $1 / 4,1 / 3,1 / 2$ \\
\hline Doors & $1 / 3,1 / 2,1 / 1$ & $1 / 3,1 / 2,1 / 1$ & $1,1,1$ & $1 / 3,1 / 2,1 / 1$ & $1 / 3,1 / 2,1 / 1$ & $1 / 4,1 / 3,1 / 2$ \\
\hline Persons & $1 / 3,1 / 2,1 / 1$ & $1 / 3,1 / 2,1 / 1$ & $1,2,3$ & $1,1,1$ & $1,2,3$ & $1 / 4,1 / 3,1 / 2$ \\
\hline Lugboot & $1 / 3,1 / 2,1 / 1$ & $1 / 3,1 / 2,1 / 1$ & $1,2,3$ & $1 / 3,1 / 2,1 / 1$ & $1,1,1$ & $1 / 4,1 / 3,1 / 2$ \\
\hline Safety & $2,3,4$ & $2,3,4$ & $2,3,4$ & $2,3,4$ & $2,3,4$ & $1,1,1$ \\
\hline
\end{tabular}

Langkah selanjutnya yang dilakukan adalah menentukan nilai bobot relatif dari masing-masing atribut dengan menghitung nilai fuzzy synthetic extent 
dengan langkah pertama pertama yang dilakukan adalah menjumlahkan tiap-tiap bilangan fuzzy dalam tiap barisnya. Berikutnya hitung total dengan menjumlahkan tiap-tiap bilangan fuzzy pada baris dan kolom. Data penjumlahan bilangan fuzzy ditampilakan Page 4 pada tabel III.

TABEL III

HASIL PENJUMLAHAN BILANGAN FUZZY

\begin{tabular}{|l|r|r|r|}
\hline & \multicolumn{1}{|c|}{$\sum \mathbf{l}$} & \multicolumn{1}{c|}{$\sum \mathbf{m}$} & \multicolumn{1}{c|}{$\sum \mathbf{u}$} \\
\hline Buying & 5,25 & 9,33 & 13,50 \\
\hline Maint & 4,58 & 7,83 & 11,50 \\
\hline Doors & 2,58 & 3,33 & 5,50 \\
\hline Persons & 3,92 & 6,33 & 9,50 \\
\hline Lugboot & 3,25 & 4,83 & 7,50 \\
\hline Safety & 11,00 & 16,00 & 21,00 \\
\hline$\sum \sum_{\boldsymbol{g}_{\boldsymbol{i}}}^{\boldsymbol{M}}$ & 30,58 & 47,65 & 68,5 \\
\hline$\frac{1}{\sum \sum_{\boldsymbol{g}_{\boldsymbol{i}}}^{\boldsymbol{M}}}$ & 0,033 & 0,021 & 0,015 \\
\hline
\end{tabular}

Setelah menghitung nilai fuzzy synthetic extent, selanjutnya akan dihitung tingkat kemungkinan fuzzy synthetic berdsarkan matriks perbandingan berpasangan yang dibentuk, diperoleh nilai fuzzy syntethic extent yang ditampilkan pada tabel IV.

TABEL IV

NILAI FUZZY SYNTHETIC EXTENT

\begin{tabular}{|l|r|r|l|}
\hline & \multicolumn{1}{|l}{} & \multicolumn{1}{|c|}{$\boldsymbol{m}$} & $\boldsymbol{u}$ \\
\hline S1 & 0,0766 & 0,1958 & 0,4414 \\
\hline S2 & 0,0669 & 0,1643 & 0,3760 \\
\hline S3 & 0,0377 & 0,0699 & 0,1798 \\
\hline S4 & 0,0572 & 0,1329 & 0,3106 \\
\hline S5 & 0,0474 & 0,1014 & 0,2452 \\
\hline S6 & 0,1606 & 0,3357 & 0,6866 \\
\hline
\end{tabular}

Setelah menghitung nilai fuzzy synthetic extent, selanjutnya akan dihitung tingkat kemungkinan fuzzy synthetic dan dicari nilai minimumnya maka diperoleh hasil seperti pada tabel $\mathrm{V}$ dan vektor bobot pada tabel VI .
TABEL V

NILAI MINIMUM BERDASARKAN KEMUNGKINAN

\begin{tabular}{|l|c|c|c|c|c|c|}
\hline & S1 $\geq$ & S2 $\geq$ & S3 $\geq$ & S4 $\geq$ & S5 $\geq$ & S6 \\
\hline S1 & & 0,905 & 0,450 & 0,788 & 0,866 & 1,000 \\
\hline S2 & 1,000 & & 0,545 & 0,886 & 0,908 & 1,000 \\
\hline S3 & 1,000 & 1,000 & & 1,000 & 1,000 & 1,000 \\
\hline S4 & 1,000 & 1,000 & 0,661 & & 0,952 & 1,000 \\
\hline S5 & 1,000 & 1,000 & 0,808 & 1,000 & & 1,000 \\
\hline S6 & 0,668 & 0,557 & 0,068 & 0,425 & 0,692 & \\
\hline Minimum & $\mathbf{0 , 6 6 8}$ & $\mathbf{0 , 5 5 7}$ & $\mathbf{0 , 4 5 0}$ & $\mathbf{0 , 4 2 5}$ & $\mathbf{0 , 6 9 2}$ & $\mathbf{1 , 0 0 0}$ \\
\hline
\end{tabular}

TABEL VI

PERBANDINGAN DATA EVALUASI PENERIMAAN MOBIL

\begin{tabular}{|c|c|c|c|c|c|}
\hline S1 & S2 & S3 & S4 & S5 & S6 \\
\hline 0,668 & 0,557 & 0,450 & 0,425 & 0,692 & 1,000 \\
\hline
\end{tabular}

Selanjutnya vektor bobot dinormalisasikan, maka diperoleh bobot kriteria untuk masing-masing atribut, yaitu:

TABEL VII

BOBOT KRITERIA MASING-MASING ATRIBUT

\begin{tabular}{|r|r|r|r|r|r|}
\hline Buying & Maint & Doors & Persons & Lugboot & Safety \\
\hline 0,196 & 0,163 & 0,02 & 0,125 & 0,203 & 0,293 \\
\hline
\end{tabular}

Berdasarkan hasil perhitungan bobot yang dilakukan, maka kriteria Safety memiliki prioritas tertinggi sebagai evaluasi penerimaan mobil sebesar 0,293 .

\section{ANALISA HASIL}

Pada tabel VIII ditunjukan bahwa hasil pengujian terhadap 1728 sampel data dengan iterasi yang berbeda, juga memerlukan waktu poses yang berbedabeda pula. Semakin besar nilai iterasinya, maka semakin lama waktu proses yang diperlukan untuk melatih (training) data. Pada iterasi (epoch) ke 500 dapat dilihat besaran waktu yang diperlukan selama proses training. Namun semakin lama data dilatih maka semakin baik hasilnya karena mendekati data aslinya. Perbandingan hasil pengujian terhadap data asli evaluasi penerimaan mobil dapat dilihat pada gambar 2.

TABEL VIII

PERBANDINGAN DATA EVALUASI PENERIMAAN MOBIL

\begin{tabular}{|c|c|c|c|c|c|c|}
\hline \multirow{2}{*}{$\begin{array}{l}\text { Jumlah } \\
\text { Sample }\end{array}$} & \multirow{2}{*}{$\begin{array}{c}\text { Epoc } \\
h\end{array}$} & \multirow{2}{*}{$\begin{array}{l}\text { Waktu } \\
\text { Proses }\end{array}$} & \multicolumn{4}{|c|}{ Hasil Pengujian } \\
\hline & & & Unacc & Acc & Good & Ygeod \\
\hline \multirow{5}{*}{1728} & 100 & $0: 54: 31$ & 0,46 & 99,54 & 0 & 0 \\
\hline & 200 & $1: 20: 27$ & 0 & 100 & 0 & 0 \\
\hline & 300 & $1: 54: 44$ & 0 & 88,83 & 4,57 & 6,60 \\
\hline & 400 & $2: 59: 34$ & 2,08 & 3,13 & 94,79 & 0 \\
\hline & 500 & $3: 44: 25$ & 80,84 & 15,05 & 2,88 & 1,23 \\
\hline \multicolumn{3}{|c|}{ Data Asli } & Unace & Acs & Good & Ygood \\
\hline Jum & Kasus & 1728 & 70,023 & 22,222 & 3,993 & 3,762 \\
\hline
\end{tabular}




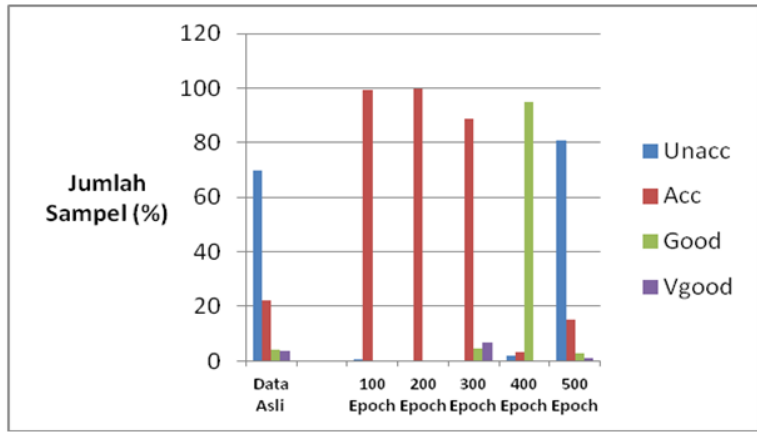

Gbr 2. Grafik Perbandingan Data Evaluasi Penerimaan Mobil

\section{KESIMPULAN}

Berdasarkan pengujian yang dilakukan pada evaluasi penerimaan mobil, dapat disimpulkan bahwa penerapan metode perceptron jaringan multilayer perceptron pada Fuzzy Analytic Hierarchy Process (FAHP) mampu meminimalkan pembuatan matriks perbandingan berpasangan dalam kasus yang bersifat multikriteria, sehingga masalah inkonsistensi dapat terhidari dalam pembentukan matriks. Hasil pengujian menunjukkan bahwa semakin lama data dilatih maka semakin baik hasinya karena mendekati data aslinya. Namun semakin banyak jumlah data yang dilatih dan diuji maka akan memerlukan waktu proses yang lama.

\section{REFERENSI}

[1] M. F. Aly and H. M. A. El-hameed, "Integrating AHP and Genetic Algorithm Model Adopted for Personal Selection," Int. J. Eng. Trends Technol., vol. 6, no. 5, p. 10, 2013.

[2] R. K. Gavade, "Multi-Criteria Decision Making: An overview of different selection problems and methods," vol. 5, p. 4, 2014

[3] Saaty, T.L, "The Analytic Hierarchy Process." 2008.

[4] H. A. Hefny, H. M. Elsayed, and H. F. Aly, "Fuzzy multicriteria decision making model for different scenarios of electrical power generation in Egypt," Egypt. Inform. J., vol. 14, no. 2, pp. 125-133, Jul. 2013.

[5] M. Khairani, "Improvisasi Backpropagation Menggunakan Penerapan Adaptive Learning Rate Dan Parallel Training," vol. 4, p. 16, 2014

[6] S. Khokhar, A. P. Memon, and M. U. Keerio, "Multilayer Perceptron Feedforward Neural Network Based Power System Stabilizer For Excitation Control System," p. 7.

[7] M. Tim Jones, Artificial Intelligence: A System Aproach New delhi: David Pallai, Infinity Science Press Llc, 11 Leavitt Street Hingham, Ma 02043, 2008. 